\title{
ACTIVIDADES DE LOS INVESTIGADORES DE ENERO A DICIEMBRE DE 1985
}

La doctora Elisa Vargas Lugo dictó dos conferencias en los ciclos organizados con motivo de las celebraciones de la Orden de San Francisco, con el tema "Representaciones de San Francisco en el arte de la Nueva España". Dos conferencias más de difusión, en CONDUMEX. Una conferencia sobre los palacios del Conde Xala y del Conde de Heras Soto.

Participó en los siguientes simposios y mesas redondas: presentó una ponencia en el Coloquio del Instituto de Investigaciones Estéticas. Tomó parte en la mesa redonda sobre Arte y Literatura, División de Estudios de Posgrado de la Facultad de Filosofía y Letras. Simposio sobre Nacionalismo organizado por el CECYDEL. Congreso Interamericano de Filosofía en la ciudad de Guadalajara.

Prestó asesoría al Comité de Arte del Instituto Mexicano Norteamericano de Relaciones Culturales. Consejo Técnico del Premio "Rafael Heliodoro Valle".

Fue jurado en la sesión VI para los Premios Nacionales. Asistió a las sesiones de las siguientes instituciones de la que es miembro: Seminario de Cultura Mexicana, ICOMOS Mexicano, Sociedad Defensora del Tesoro Artístico de México.

Continuó sus investigaciones en los archivos y la toma de fotografías para aumentar el acervo de nuestra Fototeca y redactó documentos en defensa de varios monumentos coloniales.

El maestro Xavier Moyssén fue elegido para Secretario de la Academia de Artes, el 29 de enero, el desempeño de labores es por un año.

Nombramiento por disposición del señor Secretario de Educación Pública, como miembro de la Comisión Nacional de Zonas y Monumentos Artísticos. SEP/INBA, Febrero 14.

La Dirección General de Difusión Cultural le nombró miembro del Consejo de Exposiciones de los Museos de la UNAM, marzo 10.

Designación, por parte de la Academia de Artes como miembro de la Comisión para conmemorar el centenario del natalicio de Diego Rivera; la Comisión la preside el señor Secretario de Educación Pública. Septiembre 10. 
Miembro del jurado para otorgar el Premio Nacional 1985, en la Sección de Bellas Artes, noviembre 7.

Durante el año dictó varias conferencias y participó en mesas redondas, sobre pintura y arquitectura contemporánea de México, en diversas instituciones culturales de la ciudad.

La doctora Ida Rodríguez Prampolini de enero a marzo de 1985 continuó en el cargo de Consejera de la Embajada de México en Londres, puesto que ocupó durante su año sabático 1984-1985. En enero impartió una conferencia sobre "El realismo mexicano en la pintura mexicana", Universidad de Essex, Colchester, Gran Bretaña.

El 17 de febrero presentó la exposición de David Alfaro Siqueiros en el Museo Nacional de Praga, Checoslovaquia, donde también dictó una conferencia sobre este artista y asistió a una mesa redonda de prensa sobre el "Muralismo mexicano", el 18 de febrero.

Durante su estancia en Inglaterra realizó una investigación sobre John Ruskin y William Morris que utilizará en su libro Arte por el arte - contra arte social, en preparación.

A su regreso a México fue miembro del jurado de la Bienal de grabado; además, dirigió durante cuatro meses las organizaciones culturales del periódico El Universal; asimismo impartió sus cátedras de "Introducción al arte contemporáneo" y un Seminario de dirección de tesis, en la Facultad de Filosofía y Letras y realizó un audiovisual de José Guadalupe Pos`da; el 13 de agosto impartió una conferencia en el Museo del Pueblo, Guanajuato, Guanajuato.

El 16 de agosto dió una conferencia en la Escuela de Música de la SEP, en la ciudad de Veracruz, sobre "Arte de la Revolución mexicana", misma que repitió el lunes 18 en la Casa de la Cultura de Córdoba, Veracruz.

Del 29 de noviembre al 6 de diciembre fue invitada a participar en el II Encuentro de Intelectuales por la Soberanía de los Pueblos de Nuestra América, en La Habana, Cuba. Este año le fue concedido entrar en el Sistema Nacional de Investigadores.

El arquitecto Manuel González Galván dictó las siguientes conferencias: "Aproximaciones al arte mexicano", Colegio de San Ildefonso, mayo 13; "Alegorías en la pintura novohispana", Pinacoteca Virreinal, mayo 14; 
"El barroco como esplendor virreinal", Colegio de San Ildefonso, mayo 20; "Alegorías en yeserias barrocas", en el MUNAL, junio 28; "El Palacio Nacional" Instituto Mexicano Norteamericano, Julio 15; "La arquitectura religiosa a partir de Hernán Cortés", Claustro de Sor Juana, agosto 29; "Contribución franciscana al arte mexicano", Centro Cultural Domecq, noviembre 14.

Guió al grupo, Amigos del INAH, en excursión cultural a Michoacán los días 13 a 16 de septiembre.

Fue jurado de pintura para exposiciones de la galería del Instituto Mexicano Norteamericano de Relaciones Culturales, el 6 de enero.

En el X Coloquio del Instituto de Investigaciones Estéticas celebrado del 3 al 7 de junio, intervino con la ponencia denominada "De los fustes barrocos latinoamericanos".

La doctora Beatriz de la Fuente impartió su Seminario de Investigación y Tesis de Arte Prehispánico, con el tema: "Xiuhtecuhtli y Huehueteotl, aproximación a su identidad en fuentes del siglo XVI, códices y esculturas" en la División de Estudios de Posgrado de la Facultad de Filosofía y Letras, de la Universidad Nacional Autónoma de México.

Dictó su discurso de ingreso, el 7 de mayo, como miembro de El Co. legio Nacional, con el tema: "El arte prehispánico y la educación nacional". Las palabras de salutación y bienvenida estuvieron a cargo del Presidente en turno doctor Antonio Gómez Robledo y la contestación por el doctor Rubén Bonifaz Nuño.

Organizó, en colaboración con la doctora Elisa García Barragán, Secretaria Académica del Instituto, las siguientes actividades para conmemorar el quincuagésimo aniversario del Instituto de Investigaciones Estéticas:

1. "Homenaje a los fundadores y miembros desaparecidos", ceremonia efectuada el 10. de febrero en el salón "El Generalito" del Centro Cultural San Ildefonso de la UNAM.

2. X Coloquio Internacional del Instituto de Investigaciones Estéticas: "Simpatías y Diferencias. La historia del arte en México y América Latina", del 3 al 6 de junio en el Auditorio de la Biblioteca Nacional, Centro Cultural Universitario de la UNAM.

3. Ciclo de Conferencias sobre "El arte en México", de abril a junio, en colaboración con la Dirección de Proyectos Académicos de la Universidad Nacional Autónoma de México. 
Presentó el 18 de julio, la ponencia "La obra de Román Piña Chán en relación a los olmecas" en el Simposio titulado "Vida y obra de Román Piña Chán" en el Instituto de Investigaciones Antropológicas de la UNAM.

Dictó las siguientes conferencias: "El Arte Olmeca", el 22 de abril, en San Ildefonso. "Imágenes y rostros en la plástica prehispánica", el 9 de junio, en el Museo Nacional de Arte, iniciando un ciclo de conferencias que bajo el tema "Del Arte" organizó el maestro Alberto Dallal, con motivo del quincuagésimo aniversario del Instituto. "La estructura armónica en la escultura monumental olmeca", el 27 de agosto, en la Acadèmia de Artes de México. "Peldaños en la conciencia, un acercamiento a los rostros en el arte prehispánico", el 11 de noviembre, en la Asociación Mexicana de Medicina General y Familiar.

Dictó su curso como miembro del Colegio Nacional, correspondiente al año académico del 9 al 18 de septiembre de 1985, en el edificio sede de dicho Colegio, con el tema: "De las Mujeres Bonitas a la expansión olmeca" (Inicio de la escultura en mesoamérica):

Lunes 9: "Cómo es la escultura, sitios, modos, materia, técnica".

Miércoles 11: "Esquema y Naturaleza, las Mujeres Bonitas y Xochipala".

Viernes 13: "Los olmecas, el arte monumental. Forma y significado. Su evolución”.

Miércoles 18: "Los olmecas, las piezas menores. Formas y significado. Su evolución”.

Participó los días 12 de agosto y 16 de octubre en el programa de televisión "Noticias universitarias" para informar de las actividades del Instituto.

Celebró en el mes de octubre en su calidad de Directora del Instituto, un convenio con el Departamento de Monumento Históricos del Instituto Nacional de Antropología e Historia, para que cuatro investigadores del Instituto: la maestra Martha Fernández, el maestro Marco Díaz, el maestro Rogelio Ruíz Gomar y el doctor Gustavo Curiel, colaboren con la clasificación tipológica de los monumentos del Centro Histórico de la Ciudad de México. Esta clasificación tiene como objetivo principal fundamentar la reglamentación del uso de dicho centro y de los monumentos históricos que lo integran.

Asistió, en su calidad de Vicepresidenta del Comité Internacional de Historia del Arte, a las sesiones del buró directivo de las Courtvald Galleries, los días 22, 23 y 24 de septiembre, así como al Coloquio, England an the Continent of Europe in the Gothic period, en el Museo Británico de Londres, Inglaterra. 
Fue nombrada el 16 de agosto Investigador Nacional, Nivel III, en el Sistema Nacional de Investigadores.

Fue designada, el 27 de septiembre, representante de El Colegio Nacional en el "Comité de Reconstrucción del Área Metropolitana".

La maestra Marta Foncerrada de Molina tomó parte en la presentación del libro: Los Hombres de Piedra, Escultura Olmeca, de Beatriz de la Fuente, Palacio de Minería (Capilla) el 9 de marzo a las 11:30 horas. Dictó las siguientes conferencias: "La pintura mural de Cacaxtla", en el Tecnológico de Monterrey en Lago de Guadalupe, Departamento de Difusión Cultural, el 19 de abril. "Cultura Maya", en el Colegio de San Ildefonso, Programa de Extensión Universitaria, UNAM, el 6 de mayo. "Arte Maya. Interacción artística regional", en el X Coloquio Internacional de Historia del Arte del IIE, Simpatías y diferencias. Relaciones del arte mexicano con el de América Latina, del 3 al 6 de junio, Centro Cultural Universitario, C. U., el 3 de junio. Imágenes y glifos en la pintura mural de Cacaxtla, 1er. Coloquio Internacional de Mayistas, Centro de Estudios Mayas, UNAM, Palacio de Minería, el 5 de agosto. "El regio. nalismo de Cacaxtla en la escritura glífica", XIX Mesa Redonda de la Sociedad Mexicana de Antropología, del 11 al 16 de agosto, en Querétaro, Querétaro, el 16 de agosto. "El arte en la cultura maya", conferencia impartida durante el ciclo organizado por el IIE para conmemorar su quincuagésimo aniversario que tuvo lugar en el Museo Nacional de Arte, el sábado 31 de agosto de 1985.

La doctora Elisa García Barragán colaboró con la doctora Beatriz de la Fuente en la organización de las siguientes actividades para conmemorar el quincuagésimo aniversario del Instituto de Investigaciones Esiéticas:

1. "Homenaje a los fundadores y miembros desaparecidos", ceremonia efectuada el $1^{\circ}$ de febrero en el salón "El Generalito" del Centro Cultural de San Ildefonso de la UNAM.

2. X Coloquio Internacional del Instituto de Investigaciones Estéticas: "Simpatias y Diferencias. La historia del arte en México y América Latina", del 3 al 6 de junio en el Auditorio de la Biblioteca Nacional, Centro Cultural Universitario de la UNAM. 
3. Ciclo de conferencias sobre "El arte en México" de abril a junio, en colaboración con la Coordinación de Extensión Académica y organizó la exposición de publicaciones del Instituto que tuvo lugar en el Palacio de Minería, en el mes de marzo durante la VI Feria Internacional del Libro, organizada por la Facultad de Ingeniería. Dictó las siguientes conferencias: "Las revistas artísticas y literarias durante el siglo XIX", en el Palacio de Minería", el 9 de marzo de 1985. "El Palacio de Minería", "El Museo Nacional de Arte", "El edificio de correos" y "El Palacio de Bellas Artes", en el Palacio de Minería el 21 de abril. "Arte de México Independiente" y "Renovación de la Academia de San Carlos", en San Ildefonso, el 10 de junio. "Siglo XIX Crítica y pintura", el 27 de febrero en la Escuela Nacional de Pintura, Escultura y Grabado "La Esmeralda". "Pintura mexicana del siglo xIx", el 12 de noviembre en la Facultad de Odontología, dentro de la Semana Cultural, organizada por esa Facultad.

Presentó las siguientes ponencias: "El arte y la literatura en el siglo XIX", en el Coloquio Interdisciplinario de Literatura en la Facultad de Filosofía y Letras, el 29 de agosto. "El arte en vísperas y durante la guerra de Independencia", dentro de las Mesas Redondas sobre el Arte en torno a la Independencia y a la Revolución, el 7 de noviembre, mismas que fueron organizadas por ella en colaboración con la Comisión Coordinadora de los festejos conmemorativos del Septuagésimo Quinto Aniversario de la Universidad Nacional de México 1910-1985.

Presentó los siguientes libros publicados por el Instituto de Investigaciones Estéticas: El Estridentismo en México 1921-1927, el 3 de marzo de 1985 en El Palacio de Minería. El Palacio de la Inquisición, El Palacio de Minería, El Colegio Máximo de San Pedro y San Pablo y La iglesia y el convento de San Agustín, el 27 de noviembre en Ciudad Universitaria, durante la 3a. Feria Nacional del libro en la UNAM.

Fue moderadora de todas las mesas redondas en torno al "Análisis de la política cultural de la UNAM", efectuadas los días 25,26 y 27 de septiembre en el Auditorio del Instituto de Investigaciones Bibliográficas, mesas organizadas por la Coordinación de Extensión Universitaria.

Participó los días $1^{\circ}$ y 8 de marzo en los programas de televisión: Cápsulas sobre los autores universitarios y del Quinquagésimo aniversario del Instituto de Investigaciones Estéticas y de la Dirección General de Publicaciones, para informar sobre los principales autores y las publicaciones del Instituto. 
El profesor Marco Díaz dictó las siguientes conferencias: "La catedral de León, Guanajuato", impartida durante el ciclo organizado por el IIE para conmemorar su Cincuentenario, que tuvo lugar en el Museo Nacional de Arte el sábado 3 de agosto de 1985. "Del arte y bibliotccas", impartida en la Universidad Autónoma de Puebla. En la Biblioteca José María La Fragua, el 31 de septiembre. "Problemas de identificación. Arquitectura 1800-1860", impartida en el Centro Histórico de Churubusco, organizada por la Dirección de Monumentos Históricos, el 18 de noviembre.

Presentó la ponencia "Los comportamientos de la arquitectura mexicana y argentina" en el X Coloquio Internacional de Historia del Arte, coloquio titulado: "Simpatías y diferencias. Relaciones del arte mexicano con el de América Latina", el 5 de junio, organizado por el IIE, tuvo lugar en el Auditorio de la Biblioteca Central del Centro Cultural Universitario.

El maestro Alberto Dallal obtuvo su promoción a Investigador Titular "A", Tiempo Completo, del Instituto de Investigaciones Estéticas (10. de septiembre) e ingresó en el Sistema Nacional de Investigadores. Hasta el 26 de agosto formó parte de la Comisión Editorial y hasta septiembre de la Dictaminadora de Ciencias en la Comunicación, ambas en la Facultad de Ciencias Políticas y Sociales.

Sustentó las siguientes conferencias: "Periodismo y literatura: experiencias compartidas" y "Del teatro y los actores" en el Museo Pape de Monclova, Coahuila; las mismas en el Teatro de la Ciudad de Monterrey, Nuevo León, en donde asimismo dictó un curso sobre "Análisis de las actividades dancísticas" y una conferencia titulada "Danza: las irradiaciones del cuerpo" (marzo). En abril dictó el curso "Análisis de las actividades dancísticas" en el Centro de Información y Documentación de la Danza (INBA) y en mayo "Principios de estética" en la Escuela Popular de Bellas Artes de la Universidad Michoacana de San Nicolás de Hidalgo, en Morelia. Con la ponencia titulada "Un caso notable de la experiencia dancística latinoamericana: Elena Noriega", participó en el Décimo Coloquio Internacional de Historia del Arte del Instituto de Investigaciones Estéticas (3-6 de junio) y con la titulada "El áura del cuerpo" participó en el Encuentro Internacional sobre Investigación de la Danza (6-8 de diciembre), ambos celebrados en la ciudad de México. 
Organizó el ciclo de conferencias "Del arte" que, con motivo del Cincuentenario del Instituto de Investigaciones Estéticas, tuvo lugar en el Museo Nacional de Arte de la Ciudad de México (junio a septiembre).

La maestra Alicia Azuela fue nombrada profesora del Instituto de Artes de Detroit, en Detroit Michigan, para organización de la exposición en honor de Diego Rivera que llevará a cabo ese Instituto a partir de febrero de 1986 en Detroit, Filadelfia, Berlín, Madrid, Roma y México.

Coordinó en México el catálogo para la misma exposición, y trabajó en la elaboración de la bibliografía, el provenảnce, parte de la cronología y trabajó en la preparación del artículo "Rivera and the Concept of Proletarian Art" que aparecerá en dicho catálogo.

Asistió al X Coloquio Internacional de Historia del Arte; "Simpatías y diferencias. Relaciones del arte mexicano con el de América Latina".

El doctor Aurelio de los Reyes terminó la revisión de la prensa periódica de los años 1920 a 1931, e inició la revisión de semanarios y archivos para su investigación del cine de esos años.

Realizó la investigación iconográfica para las series de programas de televisión y de libros titulados Biografías del poder. Los libros serán ocho de los cuales asesoró el año de 1985 el diseño de dos. Tomó aproximadamente 5,000 fotografías para ilustrar ambas series. Identificó material fílmico del archivo de la filmoteca de la UNAM. Identificó material fílmico del archivo Toscano, para la serie de programas de televisión titulada Testimonios. Identificó una película "Decena Trágica", encontrada por Fernando del Moral en Guanajuato. Identificó numerosas fotografías de los archivos gráficos consultados: Centro de Documentación Gráfica, del Archivo General de la Nación, Centro de Estudios de Historia de México, CONDUMEX, Centro de Estudios de la Universidad, Archivo Plutarco Elías Calles, The Library of Congress, Washington, EUA.

El doctor Julio Estrada, ha continuado con la elaboración de varios capítulos de su libro Teoría General de los Ciclos, Asociaciones y Orbi tas Interválicas en toda escala. 
Trabajó en dichos textos en la elaboración simultánea de la redacción y la preparación para la impresión en negativos, utilizando el sistema TEX en la computadora Foonley del IIMAS. Rafael Méndez, quien trabaja en un sistema de dibujo de partituras de música por medio de computadora, tendrá a su cargo la realización de todos los ejemplos musicales del libro, que será en sí mismo una innovación editorial en el país.

El doctor José Guadalupe Victoria Vicencio participó en el X Coloquio de Historia del Arte "Simpatías y Diferencias: relaciones del Arte Mexicano con el de América Latina", celebrado en el mes de junio y organizado por el Instituto de Investigaciones Estéticas, con una ponencia titulada "Patronos, artistas y obras en los virreinatos americanos durante el siglo xvi". También participó en el Noveno Congreso Interamericano de Filosofía, celebrado en noviembre en la ciudad de Guadalajara, Jal., con la ponencia titulada: "María: blasón y baluarte de México".

Participó en un seminario sobre Teoría de la Arquitectura, organizado por la Escuela de Arquitectura del Instituto Tecnológico de Monterrey (Unidad Querétaro) con dos confẹrencias sobre la "Tradición y modernidad en la arquitectura mexicana. 1888-1985".

Fue promovido a Investigador Asociado " $\mathrm{C}$ ", Tiempo Completo, en el Instituto de Investigaciones Estéticas.

Impartió quince conferencias sobre arte mexicano en la ciudad de México y en el interior del país.

La maestra Martha Fernández participó en todos los eventos que se llevaron a cabo para conmemorar el quincuagésimo aniversario del Instituto de Investigaciones Estéticas, no sólo como parte de la comisión organizadora del Coloquio, sino en actividades concretas. Tales fueron: la "Semblanza de Luis Mac Gregor", que presentó en la ceremonia conmemorativa realizada el dos de febrero de 1985 en el Salón de El Generalito del Antiguo Colegio de San Ildefonso; así mismo, presentó una ponencia titulada "Arte tequitqui y arte mestizo: el artista americano" en el Coloquio Internacional del Instituto, efectuado del 3 a 7 de junio de 1985. Finalmente, dentro de estos eventos de aniversario, dictó la conferencia "La ciudad de los palacios" el 8 de septiembre de 1985 en el Museo Nacional de Arte dentro del ciclo titulado "Del arte". 
A nivel difusión, dictó una conferencia sobre "El arte en la época colonial en México" para la comunidad de la Facultad de Filosofía y Letras de la UNAM, e impartió, para la misma dependencia, cuatro visitas guiadas: Calpan y Huejotzingo, Tlalmanalco, Malinalco y la Pinacoteca Virreinal.

Fue nombrada Investigador Nacional por la Secretaría de Educación Pública dentro, del Sistema Nacional de Investigadores. Honor que goza a partir del 1o. de junio de 1985.

Los profesores del Colegio de Historia de la Facultad de Filosofía y Letras la eligieron Consejera Académica y, a partir del 12 de marzo de 1985, funge como presidenta del Consejo Académico de dicho Colegio.

A raiz del terremoto ocurrido en México el pasado 19 de septiembre, formó parte, de noviembre a diciembre de 1985, de la Comisión que integró el Instituo de Investigaciones Estéticas para colaborar con la Dirección General de Monumentos Históricos del Instituto Nacional de Antropología e Historia en la elaboración del reglamento del Centro Histórico de la Ciudad de México, la cual fue disuelta por apartarse los objetivos del INAH de los objetivos universitarios.

El maestro José Rogelio Ruíz Gomar se ocupó de la organización de un ciclo de conferencias que para conmerorar los cincuenta años del Instituto de Investigaciones Estéticas, y en colaboración con el INBA, se llevaron a cabo en la Pinacoteca Virreinal de San Diego, bajo el título de "Nueva visión de la pintura colonial mexicana", entre los días 7 y 30 de mayo. En este evento sustentó la conferencia "El gremio de pintores en la Nueva España", 16 de mayo, misma que volvió a presentar dentro de otro ciclo de conferencias que con el mismo motivo se organizó en el Palacio de Minería, 6 de julio. Asimismo, dentro del ciclo "Historia del arte mexicano", organizado por la Coordinación de Extensión Universitaria de la UNAM, presentó una conferencia con el tema "Pintura Colonial en México" en el Colegio de San Ildefonso, 27 de mayo.

Formó parte de la comisión de este Instituto que colaboró con la Dirección de Monumentos Históricos del INAH, en la elaboración de las bases de un reglamento para la declaratoria de Zona Monumental del Centro Histórico de la Ciudad de México.

Llevó dos visitas guiadas, una a Taxco, Guerrero, 16 y 17 de marzo y otra al Museo de la Basílica de Guadalupe, 19 de mayo, dentro del programa de paseos culturales del INAH. 
La doctora Clara Bargellini continuó en sus funciones como asesora del Departamento de Historia del Arte de la División de Estudios de Posgrado de la Facultad de Filosofía y Letras.

Participó en febrero en un programa de Intercambio Académico en la Escuela de Arquitectura de la Universidad Autónoma Benito Juárez de Oaxaca sobre problemas de conservación del patrimonio monumental.

En marzo dictó una conferencia sobre la Plaza de Santo Domingo y sus monumentos para el MIT Club de México. Participó con una conferencia, sobre la iconografía de las portadas de las iglesias norteñas en el ciclo organizado en el Museo Nacional para conmemorar el Cincuentenario del Instituto de Investigaciones Estéticas. En la VII Reunión de Historiadores Mexicanos y Norteamericanos, que tuvo lugar en Oaxaca a fines de octubre, presentó una ponencia sobre las parroquias monumentales de los siglos xvil y xviII del centro norte de México. A mediados de diciembre expuso la historia urbanística de la Ciudad de México en la reunión, "Insegnamenti per i tecnici itialiani dal sisma del 19 settembre 1985 del Messico", invitada por la Facultad de Arquitectura de la Universidad de Florencia, Italia.

La doctora Elia Espinosa López dictó la conferencia "Tiempo, fuerza y ascenso en el realismo intensivo del Dr. Atl", en el Museo Nacional de Arte, el 27 de enero. El 27 de junio dictó la conferencia "Arte mexicano de 1950 a nuestros dias", en el Colegio de San Ildefonso, dentro del curso de historia del arte mexicano que organizó el Departamento de Difusión Cultural de la UNAM. El 27 de julio dictó la conferencia "La escultura erótico-fantástica de Fabienne Morin”, en el Museo Nacional de Arte, dentro del ciclo "Del arte", organizado para festejar el Cincuentenario del Instituto de Investigaciones Estéticas.

Paralelamente a todas las actividades antes mencionadas, ha realizado lá investigación principal que le auspicia el Instituto de Investigaciones Estéticas: La filosofía del arte y la crítica de arte de Gilles Deleuze.

La maestra Olga Sáenz obtuvo el tiempo completo como investigador ordinario de carrera asociado $\mathrm{A}$, en el mes de mayo, con la especialidad en arte popular. 
Continuó con la investigación sobre el juguete artesanal. Como asesora en el Museo Nacional de Arte, Departamento de Investigación, participó en la organización de la exposición "Dr. Atl, conciencia y paisaje". Y colaboró en los primeros preparativos para la presentación de la muestra "La litografía en México en el siglo xix".

Conjuntamente con el arquitecto Flavio Salamanca dictó una conferencia sobre el Museo del Chopo y el Art Nouveau en México, en el mes de noviembre. 